\title{
Erratum to: Aldo-ketoreductase 1 (AKR1) improves seed longevity in tobacco and rice by detoxifying reactive cytotoxic compounds generated during ageing
}

Kodadinne Narayana Nisarga ${ }^{\dagger}$, Ramu S. Vemanna ${ }^{\dagger}$, Babitha Kodekallu Chandrashekar, Hanumantha Rao, Amaranatha Reddy Vennapusa, Ashwini Narasimaha, Udayakumar Makarla* and Mohan Raju Basavaiah

\section{Erratum}

After publication of the original article [1] it was brought to our attention that author Kodadinne Narayana Nisarga was incorrectly included as Nisarga Kodadinne Narayana. The correct name is included in the author list of this erratum and updated in the original article.

Received: 4 May 2017 Accepted: 4 May 2017

Published online: 12 May 2017

\section{References}

1. Nisarga KN et al (2017) Aldo-ketoreductase 1 (AKR1) improves seed longevity in tobacco and rice by detoxifying reactive cytotoxic compounds generated during ageing. Rice 10:11. doi:10.1186/s12284-017-0148-3

\footnotetext{
*Correspondence: udayakumar_m@yahoo.com

${ }^{\dagger}$ Equal contributors

Department of Crop Physiology, University of Agriculture Sciences, GKVK,

Bengaluru 560065, India
} 